\title{
Halep Keçisinde Şistozoma Refleksum Kaynaklı Güç Doğum
}

\author{
Abuzer Kafar ZONTURLU ${ }^{1 *}$, Tuğra AKKUŞ ${ }^{1}$ \\ ${ }^{1}$ Harran Üniversitesi Veteriner Fakültesi Doğum ve Jinekoloji Anabilim Dalı, Şanlıurfa, Türkiye.
}

Geliş Tarihi: 17.07.2018

Kabul Tarihi: 27.05.2019

Özet: Bu olguda, güç doğum şikâyeti ile kliniğimize getirilen 4 yaşlı Halep ırkı dişi bir keçiye ait bir oğlakta Şistozoma Refleksum olgusu sunulmuştur. Hasta hikayesinde; yavru sularının akması üzerinden 12 saat geçmesine rağmen, yavruya ait ekstremitelerin vajinadan görülmediği, ıkınmaların kesildiği alınan anamnez bilgileri içerisinde yer almaktadır. Vajinal muayenede; serviksin açık olduğu, yavrunun ön ve arka ayaklarının dördünün birden pubisin önünde olduğu belirlendi. Öncelikle bir presentasyon-pozisyon bozukluğu olduğu düşünülerek, düzeltme çabası içerisine girilmiş iken bağırsaklar ve yavruya ait diğer organların ele geldiği ve başın geride olduğu hissedildi. Vajinal intrauterin muayeneye dayanarak şistozoma refleksum teşhisi konuldu. Epidural anestezi altında yapılan müdahale sonucunda yavru vajinal yolla çıkarıldı. Çıkarılan yavrunun canlı olduğu belirlendi ancak 3-5 dakika sonra öldü. Sonuç olarak, kliniğimize güç doğum şikayeti ile getirilen keçide, fetotomi veya sezaryen operasyonuna gerek duyulmadan doğum kanalında gerekli müdahaleler ile yavru çıkarılabilmiştir.

Anahtar Kelimeler: Güç doğum, Şistozoma refleksum, Keçi.

\section{Dystocia Arising from Schistosoma Reflexum in a Halep Goat}

Abstract: In this study, a Schistosoma Reflexum case of kid born from a 4 year-old Halep breed female goat, which was brought to our clinic with dystocia complaint, is presented. In patient history, the information was obtained that, extremities of the kid were not seen through vagina and straining ended although 12 hours past after amniotic fluid had drained. On vaginal examination, it was identified that cervix was open and all of the forelegs and hindlegs of the kid were in front of pubis. During the examination by considering the presentation position and in an effort to correct it, it was detected that intestines and other organs of the kid could be palpated and the head was positioned behind the extremities. Based on vaginal intrauterine examination, the case was diagnosed as schistosoma reflexum. By intervention under epidural anesthesia, the kid was extracted through vaginal route. It was determined that the extracted kid was alive; however, it died 3-5 minutes later. As the conclusion, regarding the goat, which came to our clinic with dystocia complaint, the kid was able to be extracted with necessary interventions in birth canal without needing fetotomy or caesarean operations.

Keywords: Dystocia, Schistosoma reflexum, Goat.

\section{Giriş}

Gebelik sırasında yavru ile ilgili çeşitli bozukluklar; bireysel faktörler, çevre faktörleri, kalıtsal faktörler ile enfeksiyöz etkenlere bağlı olarak şekillenmektedir (Long, 2001). Bu bozukluklardan biri olan şistozoma refleksum; göğüs ve karın boşluklarının tamamen kapanmaması ile karakterize bir gelişme anomalisidir (Roberts, 1986). Kolumna vertebralisin doğrultusunun değişmesi sonucu sakrum, koksa kemikleri ve arka bacaklar öne ve yanlara doğru giderler. Bu nedenle baş, sakruma yakın olarak yer alır (Long, 2001). Karın duvarı kapanmamış olduğundan iç organlar amniyon sıvısı içerisinde serbest halde yüzerler ve çoğunlukla ekstremitelerde ankiloz bulunur (İzgür, 1994; Long, 2001; Norman, 2007).

Şistozoma refleksum, çoğunlukla sığırlarda ancak bazen koyun, keçi ve hatta köpeklerde bile görülen nadir bir konjenital doğum defektidir (Knight, 1996). Görülme sıklığı \%0.01 ile \%1.3 arasında seyretmektedir (Roberts, 1986). Koyun ve keçilerde bu duruma bağlı güç doğum sığırlara kıyasla daha az görülmektedir. Ancak yetersiz maternal pelvik yapı, gelişimi tamamlanmamış keçilerin gebe bırakılması, uterus ve doğum kanalında anormal fetal pozisyon, fetal büyüklük, prolapsus vajina, uterus tembelliği, servikal spazm (ring womb) ve ektopik gebelik durumlarında güç doğum insidansı artmaktadır (Jackson, 2004; Scott, 2007). Şistozoma refleksum olguları fetotomi veya sezaryen operasyonu ile çıkarılır. Kendiliğinden vajinal doğum sadece küçük fetüslerde mümkündür (Kalita ve ark., 2004).

$\mathrm{Bu}$ konuda yazılmış kaynakların az sayıda olması, şistozoma refleksum olgularının sığırlarda olduğu gibi keçilerde de yaygın olarak ortaya çıktığını ancak muhtemelen birçok sporadik vakanın bildirilmediğini düşündürmektedir. Keçilerde bildirilen bu tür olguların nadir olması nedeniyle, 
Halep keçisinde görülen şistozoma refleksumun başarıyla sağaltıldığı bir olgu sunulmuştur.

\section{Olgu Tanımı}

Çalışma materyalini Harran Üniversitesi Veteriner Fakültesi Hayvan Hastanesine getirilen 4550 kg ağırlığında, 4 yaşlı Halep ırkı keçi oluşturdu. Alınan detaylı anamnez sonucunda; yavru sularının 12 saat önce geldiği ancak tüm çabalarına rağmen doğumun gerçekleşmediği öğrenildi. Hastanın genel durumu ve fiziki kondisyonu iyi olmakla birlikte doğum için herhangi bir çaba sarf etmediği dikkatimizi çekti. Hastanın klinik muayenesinde; vücut ISISI $39.5^{\circ} \mathrm{C}$, nabız ve solunum normaldi. Mükoz membranlar pembe ve kapiller dolum zamanı 2 sn'den azdı. Fiziksel muayenede; vulvanın normal görünümlü ve pembemsi renk değişiminin halen korunduğu belirlendi. Dış bakıda görünürde abdominal/uterus kontraksiyonları ya da kasılmaları yoktu. Memenin muayenesinde, dolu olduğu ve süt sekresyonu geldiği tespit edildi. Lidokain/adrenalin ile epidural blok altında yapılan intravajinal muayenede, tamamen açık servikste yavruya ait kısımlar ve bağırsak belirlendi. Illk etapta bir uterus yırtığı şüphesine rağmen intrauterin muayene ve uterusun endometriyumun dikkatli bir şekilde muayenesinde herhangi bir yırtık saptanmadı. Intrauterin muayenede, kolumna vertebralisin doğrultusunun değişmiş, sakrum, koksa kemikleri ve arka bacakların öne ve yanlara doğru olduğu belirlendi. Başın ise sakruma doğru yakın bir yerde olduğu saptandı. Karın duvarının kapanmamış, iç organların amniyon sıvısı içerisinde serbest halde yüzdüğü ve ekstremitelerde hafif bir ankiloz olduğu belirlenerek şistozoma refleksum tanısı konuldu (Şekil 1).

Retropulsiyon ve manuel traksiyon ile güç doğum oluşturan yavru vajinal yolla çıkarıldı. Çıkartılan yavrunun canlı olduğu belirlendi ancak 3-5 dakika sonra öldü. Yavrunun çıkarılmasını takiben operasyon sonrası herhangi bir komplikasyon şekillenmemesi için koruyucu olarak anne için uterusa 2-3 adet oblet bırakıldı (Devamisin oblet ${ }^{\circ}$ ) ve intramüsküler olarak 5 gün süreyle 24 saatte bir $1 \mathrm{mg} / \mathrm{kg}$ Seftiofur hidroklorid (Ceftivil ${ }^{\circ}$ ) verildi. Ayrıca hayvana intravenöz yoldan genel durumunu destekleyici olarak sıvı tedavisi (400 ml \%5 dekstroz, $600 \mathrm{ml} \% 0.9$ izotonik) uygulandı. Bir hafta sonra hayvan sahibinden keçinin genel durumunun iyi olduğu bilgisi alındı.

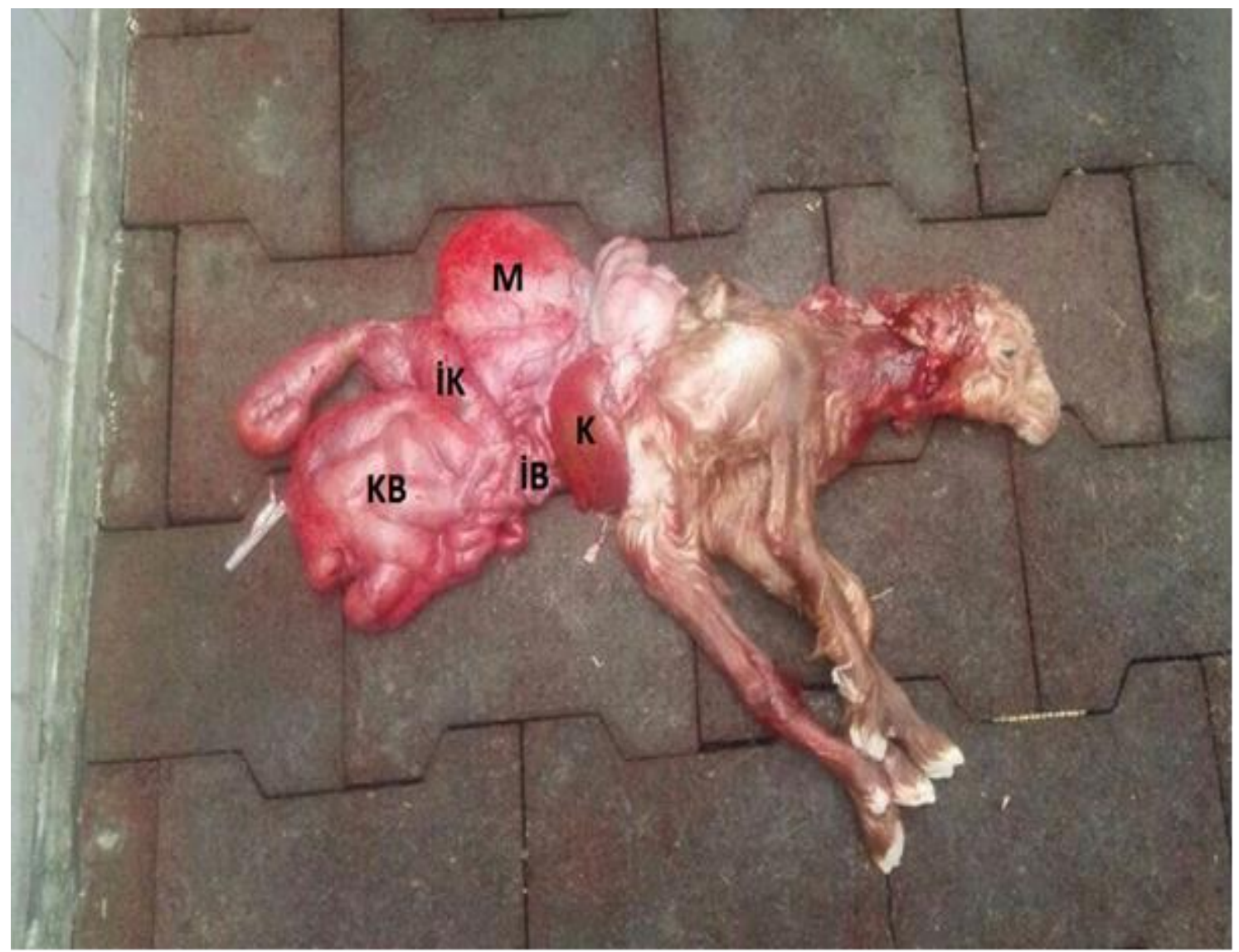

Şekil 1. Vajinal yolla çıkarılan yavru. M: mide, K: karaciğer, iB: ince bağırsak, KB: kalın bağırsak, í: idrar kesesi. 


\section{Tartışma ve Sonuç}

Sunulan olgu gösterdiği özellikler ile doğuştan bir defekt sendromu olan şistozoma refleksum tanımını doğrulamaktadır. Sendrom; abdominal is organların dışarı çıkması, omurga inversiyonu ve kafaya bitişik ankilozlu ekstremitelerdir. Şiddetli omurga inversiyonu kafanın sakruma yaklaşmasına (Roberts, 1986), organ ve sistemleri arasında düzensiz konumlanmaya neden olmaktadır (Cavalieri ve Farin, 1999).

$\mathrm{Bu}$ olguda görülen hipoplastik akciğerler, pulmoner lob anormallikleri ve diyaframın eksik oluşmuş olması diğer türlerde bildirilen olgularla benzerdir (Fatimah ve ark., 1981). Yapılan çalışmalar akciğerlerin normalin yaklaşık yarısı büyüklükte olmasının şistozoma refleksum olgularının ayırt edici bir özelliği olabileceğini düşündürmüştür (Cavalieri ve Farin, 1999). İ̧ organların dışarı çıkma derecesi ve omurga inversiyon derecesi şistozoma refleksum olgusu boyutunun farklı olmasına neden olmaktadır (Knight, 1996). Olgumuzda, ventral toraksın kapanmaması; tam bir sternal yarık, geri dönmüş göğüs kafesi ve torasik iç organların açıkta kalmasıyla sonuçlanmıştır. Bu gözlemler hem şistotoraks hem de şistosoeli görülen diğer çalışmalarla uyumludur (Cavalieri ve Farin, 1999; Knight, 1996). Yalnızca abdominal açıkık olan olgular da bulunmaktadır (Bezek ve Frazer, 1994; Cavalieri ve Farin, 1999) ancak bu olguda kalbin görünüyor olması sternum yarı̆̆ı olan şistozoma refleksum olgusuyla ilişkilidir.

Sunulan olgu, torasik ve lumbal vertebraları etkileyen omurga inversiyonudur. Ancak yapılan çalışmalarda omurga inversiyon derecesinde farklııklar olduğu belirtilmiştir (Bezek ve Frazer, 1994; Cavalieri ve Farin, 1999). Sıklıkla omurgada ankiloz şekillenmekte ve omurgaya manipülasyon yapmak son derece zor olmaktadır (Fatimah ve ark., 1981). Olgumuzda skolyoz varlığı ve diğer görünümler yapılan çalışmalarla benzerdir. Omurga kemerinin torasik kısmı, yarık sternum ile birlikte; kaburgaların, aorta ve kaudal vena kavanın anormal lokasyonunda görünümünden sorumludur. Şistozoma refleksumda pelvis deformasyonu, kafatasının kaudal kemikleri ve dönmüş omurga arasında sıkıştırma ve omurga inversiyonu sonucuyla oluşmaktadır (Roberts, 1986). Ayrıca simfisis pubis oluşumunun zaman zaman olmadığı belirlenmiştir (Jubb ve Kennedy, 1963). Sunulan olguda sadece pelviste deformasyon belirlenmiştir.

Yapılan çalışmalarda şistozoma refleksum olgularında buzağılarda torasik ve bel omur sayısının azaldığı (Fatimah ve ark., 1981), hidrosefalusla beraber görüldüğü (Bugalia ve ark., 1982), iki olguda skrotumda çatallaşma ve delinmemiş anüsle
(Cavalieri ve Farin, 1999) karşılaşıldığı belirtilmiştir. Doğan ikiz kuzularda eş zamanlı skrotum çatallaşması ve atreziya ani görülmüştür (Dennis, 1972). Şistozoma refleksum olgularında, skrotal çatallaşma ve atreziya ani arasında bir bağlantı olduğu düşünülmektedir. Kuzularda çift taraflı kriptorşidi olguları da bildirilmiştir (Dennis ve Meyer, 1965). Olgumuzda yapılan incelemelerde belirtilen durumlarla karşılaşılmamıştır. Şistozoma refleksumda dişi ürogenital kanalda veya sistemde anormalite olan olgular bildirilmiştir. Laughton ve ark. (2005), sol kornu uteride şişkinlik, sağ kornu uteride, vajina, servikste agenezis tespit etmişlerdir. Sol ovaryumun rudimenter, sağ ovaryumun olmadığı ve üretranın dilate olduğunu bildirmişlerdir. Ayrıca uterus dokusunda Müller kanalı kalıntısı olarak tahmin edilen bölmesel oluşuma rastlamışlardır (Laughton ve ark., 2005). Yapılan çalışmalarda ayrıca şistozoma refleksum olgularında kardiak oryantasyon, distal kaburga yapışıkığı ve hipoplastik skapula bulguları bildirilmiş; nedeninin omurga inversiyon bölgesinde doku basıncından kaynaklanan lokal büyüme kısıtlaması olduğu belirtilmiştir (Laughton ve ark., 2005). Olgumuzda sindirim sistemi kusurları olarak; anormal derecede ve lokasyonu değişmiş bir karaciğer, mide, küçük bir omentum ve gergin rektum önceki çalışmalarla uyumludur (Laughton ve ark., 2005; Roberts, 1986).

Şistozoma refleksum olgularına neden olan embriyolojik mekanizma bilinmemektedir. Ancak ventral duvar kapanma kusurlarının embriyonun gastrulasyon aşamasından hemen sonra, erken dönemde meydana geldiği bildirilmiştir (Loughton ve ark., 2005). Şistozoma refleksum olgularıyla beraber seyreden ürogenital defektler, mezoderm (ürogenital sistem prekürsörü) mekanizmasının etkilenmesiyle oluştuğunu düşündürmüştür (Carlson, 1999).

Son zamanlarda koyunlarda (Bhattacharyya ve ark., 2012; Matunrayo ve ark., 2015; Tsuma ve Abuom, 2008), keçilerde (Suthar ve ark., 2011), sığırlarda (Patel ve ark, 2015; Selvaraju ve ark., 2010) şistozoma refleksum olguları bildirilmiş ancak organ bazında muayeneleri yapılmamıştır.

Sonuç olarak, kliniğimize güç doğum şikayetiyle getirilen gebe bir keçide tespit edilen şistozoma refleksum olgusu başarılı bir şekilde sağaltıldı. Erken müdahale ile anne için yüksek mortalite riski bulunan gebelik patolojisi olgusunun komplikasyon şekillenmeksizin müdahalesi gerçekleştirilmiştir.

\section{Kaynaklar}

Bezek DM, Frazer GS, 1994: Schistosomus reflexus in large animals. Compend Contin Educ Vet Pract, 16, 1393-1394. 
Bhattacharyya HK, Dar SH, Fazili MR, Hafiz A, 2012: A typical case of hydrallantois accompanied by fetal monstrosity in a local ewe of Kashmir. Vet Res Forum, 3 (3), 221-223.

Bugalia NS, Verma SK, Khar SK, Khan MZ, 1982: Schistosomus reflexus in a Haryana cow. Haryana Vet, 21, 38-40.

Carlson BM, 1999: Human embryology and developmental biology, 2nd ed. St Louis, MO, Mosby, USA.

Cavalieri J, Farin PW, 1999: Birth of a Holstein freemartin calf co-twinned to a schistosomus reflexus fetus. Theriogenology, 52, 815-826.

Dennis SM, 1972: Schistosomus reflexus in conjoined twin lambs. Vet Rec, 90, 509-510.

Dennis SM, Meyer EP, 1965: Schistosomus reflexus in a sheep. Vet Rec, 47, 1386-1388.

Fatimah I, Bongso TA, Chooi KF, 1981: Schistosomus reflexus in a bovine calf: a case report. $J$ Vet Malays, 13, 40-42.

İzgür H, 194: Gebelik patolojisi. In "Evcil Hayvanlarda Reprodüksiyon Suni Tohumlama Doğum ve Infertilite", Ed; Alaçam E, Dizgi evi, Ankara.

Jackson PGG, 2004: Postparturient problems in the dog and cat. In "Handbook of Veterinary Obstetrics", Ed; Jackson PGG, 2th ed, London: WB Saunders.

Jubb KF, Kennedy PC, 1963: Pathology of Domestic Animals, Vol. 1, Academic Press, New York, USA.

Kalita D, Bhuyan D, Mukit A, Islam S, 2004: Dystocia due to Schistomus reflexus in a goat. Indian J Anim Reprod, 25 (1), 76-77.

Knight RP, 1996: The occurrence of schistosomus reflexus in bovine dystocia. Aust Vet $J, 73,105-107$.

Laughton KW, Fisher KRS, Halina WG, Partlow GD, 2005: Schistosomus reflexus syndrome: a heritable defect in ruminants. Anat Histol Embryol, 34, 312-318.
Long S, 2001: Abnormal development of the conceptus and its consequences. In "Arthur's Veterinary Reproduction and Obstetrics", Ed; Noakes DE, Parkinson DJ, England GCW, 8th ed., London: Saunders, England.

Motunrayo AH, Ogechi NR, Bire GD, Tagwai KJ, Omolathebu OJ, 2015: Dystocia due to schistosomus reflexus (cojoined twins) in a Yankassa ewe. J Coast Life Med, 3(4), 333-335.

Norman S, Youngquist RS, 2007: Parturition and dystocia. In "Current Therapy in Large Animal Theriogenology", Ed; Youngquist RS, Threlfall WR, 2nd ed, Saunders, Elsevier.

Patel A, Yadav SS, Yadav D, Sonker V, Saxena A, 2015: Dystocia due to schistosoma reflexus in a Hariana cow. Int J Livest Res, 5(4), 122-124.

Roberts SJ, 1986: Veterinary Obstetrics and Genital diseases (Theriogenology). 3rd ed., Woodstock VI, New York, USA.

Scott PR, 2007: Sheep medicine. Manson Publishing, London.

Selvaraju M, Napolean RE, Ravikumar K, Palanisamy M, Prabaharan V, Ravi R, Chandrahasan C, 2010: Dystocia due to schistosomus reflexus in a cow - a case report. J Vet Anim Sci, 41, 71-72.

Suthar DN, Sharma VK, Dabas VS, Bhoi DB, 2011: Pervaginal handling of schistosomus reflexus as a cause of dystocia in a goat. Vet World, 4(7), 330-331.

Tsuma VT, Abuom TO, 2008: A case report of schistosomus reflexus in a lamb. The Kenya Veterinarian, 32 (1), 41-43.

*Yazışma Adresi: Abuzer Kafar ZONTURLU Harran Üniversitesi, Veteriner Fakültesi, Doğum ve Jinekoloji Anabilim Dalı, Şanlıurfa, Türkiye.

e-mail: azonturlu@harran.edu.tr 